\title{
Entre el extractivismo y la defensa de la democracia. Mecanismos de democracia directa en conflictos socioambientales de América Latina
}

\author{
Between extractivism and the democracy defense: Direct \\ democracy mechanisms in Latin America's \\ socio-environmental conflicts
}

SANDRA HINCAPIÉ

Universidad Autónoma de Zacatecas (MÉXICO)

Artículo recibido: 28 enero 2017

Solicitud de revisión: 10 mayo 2017

Artículo aceptado: 26 mayo 2017

Resumen

En este artículo se analizan los mecanismos de democracia directa activados en medio de conflictos socioambientales en América Latina. Demuestra que dichos mecanismos están jugando un papel fundamental, al convertirse en un importante recurso de movilización y acción colectiva «desde abajo», mientras los gobiernos centrales, «desde arriba», han tratado de limitar su alcance o prohibir su implementación, en la medida que ponen en el debate público las consecuencias del modelo económico orientado a la apropiación extractivista de los recursos naturales.

Palabras clave: extractivismo, democracia local, conflictos socioambientales, consulta popular, consulta previa.

\begin{abstract}
This article analyzes the direct democracy mechanisms activated in middle of socioenvironmental conflicts in Latin America. It demonstrates that these mechanisms are playing a fundamental role, becoming an important resource for mobilization and collective action "from below», while central governments «from above» have tried to limit the far reaching or prohibit the implementation of that, in view of that these mechanisms puts in the public debate the consequences of the economic model aimed at extractivist appropriation of natural resources.
\end{abstract}

Keywords: Extractivism, local democracy, socio-environmental conflicts, referendum, previous consultation 


\section{INTRODUCCIÓN}

El aumento de los conflictos socioambientales por el cuestionamiento del consenso extractivista como política económica de los gobiernos en América Latina ha unido en el escenario público a diversos actores que combinan agendas de movilización como el ecologismo y las reivindicaciones por el reconocimiento de comunidades étnicas con la demanda por el derecho a participar y decidir de manera directa en la planeación del desarrollo territorial local (Gudynas, 2014; Toledo et al., 2013; Svampa, 2013; Lissidini, 2015; Martínez-Alier, 2011; Leff, 2004).

El extractivismo se caracteriza por la apropiación de grandes volúmenes de recursos naturales, bajo procedimientos de alta intensidad, que están orientados esencialmente a la exportación de materias primas o productos con un procesamiento mínimo (Gudynas, 2013;Acosta, 2012). Desde la colonia,América Latina ha sido insertada en el mercado global como proveedora de materias primas, en una relación de dependencia de las economías centrales (O'Connor, 2001). Este modelo primario-exportador se ha intensificado en las últimas décadas gracias al aumento exponencial de la demanda de recursos naturales, donde China ha jugado un papel fundamental, incrementando la presión sobre los bienes comunes (Bollier, 2014) y favoreciendo procesos de «acumulación por despojo» (Harvey, 2004).

En la medida que se expande la frontera extractivista, se han transformado radicalmente entornos locales por la depredación voraz de recursos esenciales para la reproducción de la vida, convirtiendo bienes compartidos como el agua en mercancías privadas y costosas, debido, entre otros motivos, a la contaminación de cuencas y ríos, así como a la sobreexplotación de acuíferos por los grandes volúmenes utilizados en la extracción de minerales como el oro. La titulación por parte de los gobiernos nacionales de extensos territorios para el desarrollo de proyectos extractivos, así como los daños ya causados, han propiciado la movilización de diversos colectivos que se resisten a la imposición de la política económica configurando intensos conflictos socioambientales en toda América Latina.

En este escenario de alta conflictividad social, las comunidades locales afectadas han demandado la aplicación de Mecanismos de Democracia Directa -MDD-, como la Consulta Previa y la Consultas Populares locales, para pronunciarse sobre la planeación del desarrollo territorial y las formas de aprovechamiento de los recursos naturales que implican los proyectos extractivistas. Los MDD cobran relevancia en los conflictos socioambientales en la medida que, por un lado, permite expresar de manera clara 
las decisiones ciudadanas sobre el acceso, control y/o formas de aprovechamiento de los recursos naturales y el territorio en que estos se encuentran; $y$, por otro lado, son dispositivos que vinculan la acción colectiva con las organizaciones y agentes estatales, traduciendo las demandas ciudadanas al lenguaje institucional buscando obligar la respuesta estatal.

En este artículo analizo dichos mecanismos de democracia directa y argumento que están jugando un papel fundamental en los conflictos socioambientales de la última década, al convertirse en un importante recurso de movilización y acción colectiva "desde abajo», mientras los gobiernos centrales «desde arriba» han tratado de limitar su alcance o prohibir su implementación, en la medida que pone en el debate público las consecuencias del modelo económico orientado a la apropiación extractivista de los recursos naturales.

El artículo está organizado de la siguiente manera: primero, analizo los mecanismos de democracia directa y el diseño institucional de la Consulta Previa y las Consultas Populares incorporados en las últimas décadas en los países latinoamericanos. Segundo, analizo dos formas en que han sido utilizados los MDD en los conflictos socioambientales: por un lado, como parte de los procesos de «institucionalización de la participación» a través de las disposiciones legales «desde arriba» o, por otro lado, de manera no convencional, como estrategia de acción colectiva por parte de la sociedad organizada «desde abajo». Examino las tensiones entre actores y respuestas de los gobiernos frente a la movilización y saco conclusiones comparadas de los casos.

\section{MECANISMOS DE DEMOCRACIA DIRECTA Y EXTRACTIVISMO}

Las disputas sobre quiénes y cómo participan en la comunidad política ha sido el pilar fundamental sobre el cual se ha construido el estado moderno y, más recientemente, nuestras instituciones democráticas. Las diversas luchas sociales a lo largo del tiempo han ido tejiendo diversos mecanismos institucionales para conectar las demandas sociales de reconocimiento y redistribución con las organizaciones estatales. En ese sentido, en los contextos estatales, el núcleo de lo que conocemos como derechos es el resultado de las luchas por la distribución de recursos de poder, así como su ratificación, sanción, realización y garantía (Sen 2010: 234; Tilly, 2007; Stammers, 2009; Held, 1997). En ese sentido, entiendo los derechos como horizontes normativos y proposiciones éticas que sirven 
de marco tanto para la acción estatal -al traducirse en mecanismos que generan expectativas y posibilidad de exigibilidad a través de los dispositivos jurídicos establecidos nacional e internacionalmente-, como también para la acción colectiva de personas y colectivos sociales como recursos de movilización.

América Latina en las últimas décadas ha experimentado importantes transformaciones constitucionales mediante las que se han incorporado diversos mecanismos de participación para el ejercicio de la democracia directa (Lissidini y otros, 2014). Los mecanismos de democracia directa son definidos como:

un conjunto de procedimientos que permiten a los ciudadanos tomar decisiones políticas directamente a través de un voto más allá de las elecciones regulares de representantes. Estos procedimientos están regulados por la constitución o por la ley [...]. Los resultados de la activación de estos mecanismos pueden ser vinculantes o meramente consultivos (Ruth y otros, 2017: 1).

La «institucionalización de la participación» en las constituciones, a través de la incorporación o ampliación de mecanismos de democracia directa, es indicativa de los procesos de democratización de los países. Sin embargo, como bien lo ha establecido Alicia Lissidini, la distinción fundamental sobre quienes están autorizados a activar los mecanismos de democracia directa, bien sea desde los poderes del estado «desde arriba»o desde los ciudadanos «desde abajo», condiciona cómo de participativas son las democracias (Lissidini, 2015: 140-141).

La demanda de activación de mecanismos de democracia directa por parte de los ciudadanos en medio de conflictos socioambientales como respuesta a la profundización del modelo extractivista se ha concentrado en dos tipos: la consulta previa y las consultas populares locales. La Consulta Previa es un mecanismo establecido en el Convenio 169 de la Organización Internacional del Trabajo, a través del cual se insta a los Estados a respetar y valorar la diversidad y cultura de las comunidades étnicas, reconociendo sus derechos en diversos ámbitos (Anaya, 2011). El derecho a la consulta y consentimiento libre, previo e informado es una parte central del Convenio 169, donde las comunidades étnico-raciales ya no son consideradas como objetos de políticas y proyectos de desarrollo, sino sujetos activos en la toma de decisiones con diferente grado de obligatoriedad según el impacto potencial sobre sus vidas y los territorios ocupados (Rodríguez y Morris, 2010). 
Aunque las redes de presión transnacional han sido decisivas en la divulgación y promoción de los derechos humanos alrededor del mundo, el nivel estatal es fundamental para determinar las diversas interpretaciones que se hacen de los derechos, sus alcances y limitaciones. ${ }^{1}$ En ese sentido, el Convenio de la oIT ha sido ratificado discrecionalmente por parte de los estados, y del mismo modo, algunos de sus presupuestos han encontrado desarrollo constitucional o legal al interior de los países, en algunos casos para hacer más amplio el reconocimiento de derechos de las comunidades étnicas, o por el contrario para restringir el alcance de los procesos de consulta.

Al ser la Consulta Previa un mecanismo de participación respaldado por el Derecho Internacional orientado a la promoción de los Derechos Humanos, este proporciona unos estándares que sirven como base de actuación y reivindicación de la acción colectiva en cada país (Rodríguez y Morris, 2010). Por el contrario, las Consultas Populares son mecanismos de participación derivados del reconocimiento interno del derecho político a participar más allá de la elección de representantes a cargos de públicos. Para el caso de las Consultas Populares el derecho internacional no interviene, ya que los estándares internacionales protegen un contenido mínimo de parámetros convencionales para el respeto de los derechos a la participación política, dejando una amplia autonomía a los Estados para que organicen sus instituciones políticas de acuerdo a los equilibrios internos (Bernales, 2006).

Debido a lo anterior, los diseños institucionales que regulan las formas de participación directa en los asuntos públicos de cada país, donde se inscriben las Consultas Populares, presentan una amplia variedad de mecanismos difícilmente homologables, debido a la pluralidad conceptual o terminológica, como también a las formas de regulación y aplicación. En la gran mayoría de los casos, dichos mecanismos han tenido poca aplicación - a pesar de estar contemplados constitucionalmente- y fueron convocados «desde arriba», bien por el ejecutivo o por los congresos (Zovatto, 2014: 13-70).

1 Algunos autores han atribuido un carácter colonialista que viene del norte hacia el sur en la divulgación de derechos humanos (Dezalay y Garth, 2008; De Sousa, 2014). Sin embargo, se ha demostrado cómo estas redes de presión trasnacional han contado con organizaciones de derechos humanos del sur global desde sus inicios. Así mismo, investigaciones recientes han demostrado que, antes de la proclamación de la Declaración Universal de los Derechos Humanos los propios gobiernos sudamericanos habían discutido y aprobado declaraciones en conjunto donde se señalaba la importancia de construir mecanismos supranacionales de protección de los derechos humanos que hicieran posible su garantía (Sikkink, 2014). 
Como observamos en la tabla 1 las Consultas Populares Locales solo pueden ser activadas por las autoridades estatales «desde arriba», a excepción de Ecuador y Bolivia, donde pueden ser activadas por la ciudadanía si cuentan con el respaldo del $10 \%$ del padrón electoral.

En Argentina, la posibilidad de realización de Consultas Populares Locales depende de las Constituciones Provinciales y las Cartas Orgánicas Municipales; dieciséis de veintitrés Provincias contemplan el derecho de consulta popular o referéndum (Arques, 2014: 18-39). ${ }^{2}$ Por su parte, en Colombia, la Constitución de 1991 sentó las bases para una democracia participativa, estableciendo diversas «formas de participación del pueblo en ejercicio de su soberanía», tales como «el voto, el plebiscito, el referendo, la consulta popular, el cabildo abierto, la iniciativa legislativa y la revocatoria del mandato»-Art. 103-, que fueron reguladas posteriormente por medio de la Ley de mecanismos de participación ciudadana de 1994. Las Consultas Populares pueden realizarse a nivel nacional, departamental, municipal, distrital o local, convocada por el Presidente de la República, el gobernador o el alcalde, según sea el caso, para que la ciudadanía se pronuncie sobre algún asunto de interés público y es de obligatorio cumplimiento -Art. 8 y Art. 50, 1994.

En Guatemala, según el Decreto 12-2002, en sus artículos 64, 65 y 66 establece que el Consejo Municipal puede llegar a convocar Consultas Populares Locales a petición de la ciudadanía o por petición de las comunidades indígenas, cuando sea aprobada la petición con el voto de las dos terceras partes del total de sus integrantes (Congreso de la República, 2002: 20-21). En Costa Rica, las Consultas Populares pueden iniciarse por medio de convocatoria del Consejo Municipal, que es el órgano competente para convocar a plebiscitos, referendos y cabildos a escala cantonal (Tribunal Supremo de Elecciones, 1998: 3).

2 Las Constituciones Provinciales de 16 Provincias reconocen el derecho: Córdoba, Chaco, Chubut, Entre Ríos, Río Negro, Salta, San Juan, San Luis, Tierra de Fuego, Formosa, La Rioja, Neuquén, Santa Cruz, Santiago del Estero, Corriente, Misiones, Catamarta. 
Tabla 1

Estado del reconocimiento de mecanismo de democracia directa de iniciativa popular a nivel local en América Latina

\begin{tabular}{|c|c|c|c|c|c|c|}
\hline \multirow[t]{2}{*}{ Pais } & \multicolumn{3}{|c|}{ Consulta Previa de los pueblos indigenas } & \multicolumn{3}{|c|}{ Consulta Popular Local / Referéndum Local } \\
\hline & $\begin{array}{c}\text { Año de } \\
\text { ratificación } \\
\text { Convenio OIT }\end{array}$ & $\begin{array}{c}\text { Reconocimiento } \\
\text { constitucional de la } \\
\text { CP y de los tratados }\end{array}$ & $\begin{array}{l}\text { Derechos } \\
\text { conexos }\end{array}$ & $\begin{array}{l}\text { Constitución/ Ley/ } \\
\text { Decreto }\end{array}$ & Desde arriba & Desde abajo \\
\hline Argentina & 2000 & - & - & $\begin{array}{c}\text { Const. 1994:Art.5,10 } \\
3 \\
\end{array}$ & $\mathrm{x}$ & - \\
\hline Brasil & 2002 & NINGUNA & Art.216,231 & \begin{tabular}{|c|} 
NO \\
\end{tabular} & - & - \\
\hline Uruguay & NO & - & - & NO & - & - \\
\hline Colombia & 1991 & Tratados: Art. 93 & $\begin{array}{c}\text { Arts. } \\
1,7,63,68,287, \\
329,330 \\
\end{array}$ & $\begin{array}{c}\text { Const.1991: Art.103/ } \\
\text { Ley } 134 \text { de } 1994\end{array}$ & $\mathrm{x}$ & - \\
\hline Chile & 2008 & - & - & NO & - & - \\
\hline Ecuador & 1998 & $\begin{array}{c}\text { Const. 2008. Art. } 1, \\
\text { Reconocimiento de CP } \\
\text { Art. } 57 \\
\end{array}$ & - & $\begin{array}{l}\text { Const. 2008. Ley } \\
\text { Orgánica } 2010\end{array}$ & $\mathrm{X}$ & $\begin{array}{c}\mathrm{X} \\
\text { (10\% padrón } \\
\text { electoral) } \\
\end{array}$ \\
\hline Perú & 1993 & $\begin{array}{l}\text { IV Disposición Final y } \\
\text { Transitoria/Ley de } \\
\text { Consulta Previa (2011) }\end{array}$ & $\begin{array}{l}\text { Arts } 2,19,88 \text {, } \\
89,149,191\end{array}$ & $\begin{array}{c}\text { Const. 1993: Art. 2,31 } \\
, 197\end{array}$ & $\mathrm{x}$ & - \\
\hline Venezuela & 2002 & - & - & NO & - & - \\
\hline Paraguay & 1993 & - & - & NO & - & - \\
\hline Bolivia & 1991 & $\begin{array}{c}\text { Reconocimiento } \\
\text { explicito de CP } \\
\text { ConstituciónArt.30.II.1 } \\
5 \\
\text { Tratados: Art.410 } \\
\end{array}$ & $\begin{array}{l}\text { Arts.11.II.1;2, } \\
\text { 190,192,290, } \\
293,294,295, \\
342,352,403\end{array}$ & $\begin{array}{l}\text { Ley Marco } 2008 \text { : } \\
\text { Art. } 6,7,8\end{array}$ & $\mathrm{X}$ & $\begin{array}{c}\mathrm{X} \\
\text { (10\% padrón } \\
\text { electoral) }\end{array}$ \\
\hline Panamá & NO & - & - & NO & - & - \\
\hline Guatemala & 1996 & Tratados: Art.46 & $\begin{array}{l}\text { Arts. } 58,60 \\
62,66,67,68\end{array}$ & $\begin{array}{c}\text { Cód. Mpal. Decreto } \\
12 / 2002 \text {. } \\
\text { Art. } 63,64,65,66 \\
\end{array}$ & $\mathrm{X}$ & - \\
\hline Nicaragua & 2010 & - & - & NO & - & - \\
\hline Honduras & No & - & - & NO & - & - \\
\hline El Salvador & NO & - & - & NO & - & - \\
\hline Costa Rica & 1993 & - & - & Decreto $\mathrm{N}^{\circ} 27.895$ & $\begin{array}{l}\text { Consejo } \\
\text { Municipal }\end{array}$ & - \\
\hline México & 1990 & $\begin{array}{c}\text { Reforma Constitución } \\
2011\end{array}$ & - & NO & - & - \\
\hline
\end{tabular}

Fuente: Elaboración propia

En Perú, la Constitución establece en sus artículos $31 .^{\circ}$ y $197 .^{\circ} \mathrm{el}$ derecho ciudadano de participar en los asuntos públicos y en el gobierno municipal de su jurisdicción e insta a que las municipalidades «promueven, apoyan y reglamentan la participación vecinal en el desarrollo local». Del mismo modo, la Ley Orgánica de Municipalidades en el Título VIII dedicado a «Los derechos de participación y control vecinal», dispone que las municipalidades promuevan la participación vecinal en la formulación, debate y concertación de sus planes de desarrollo, presupuesto y gestión -Art. 
112-, instituye siete instrumentos de participación ciudadana dejando abierto que las propias municipalidades reglamenten la misma «mediante uno o más de los mecanismos» de participación ciudadana, reconoce diversas figuras e instrumentos de los vecinos y de las municipalidades en materia de participación ciudadana. Asimismo, el artículo $113^{\circ}$ la Ley Orgánica de Municipalidades instituye siete instrumentos de participación ciudadana - referéndum, consultas vecinales, audiencias públicas, cabildos y asambleas populares, entre otros - dejando abierto que las propias municipalidades reglamenten la misma «mediante uno o más de los mecanismos» de participación ciudadana -Art. 113.

\section{LOS MECANISMOS DE DEMOCRACIA DIRECTA EN ACCIÓN}

Como observamos en la tabla 1 , la gran mayoría de países han ratificado el Convenio 169 de la orT y algunos han reconocido explícitamente en sus constituciones el respeto por la diversidad cultural de los pueblos. Sin embargo, el comportamiento de los gobiernos estatales en Latinoamérica se caracteriza por el incumplimiento sobre la aplicación a cabalidad de la Consulta Previa como mecanismo de democracia directa que busca el consentimiento libre, previo e informado de las comunidades étnicas sobre cualquier proyecto que pueda tener un impacto el territorio que habitan. Las investigaciones y estudios comparados sobre la implementación de la Consulta Previa en diversos países subrayan que, en los pocos países donde ha sido aplicado el mecanismo, ha sido utilizado por gobiernos y empresas como un trámite burocrático para la aprobación de sus proyectos, con baja o nula incidencia de las comunidades (Puyana, 2016; Martínez, 2015; DPLF, 2015).

En Colombia, el derecho a la Consulta Previa ha tenido reconocimiento constitucional y una amplia jurisprudencia de la Corte Constitucional, que ha obligado a los diferentes gobiernos a robustecer los procesos institucionales para garantizar la consulta y el consentimiento de las comunidades étnicas. En ese sentido, el Estado colombiano es el único que cuenta con una instancia especializada y centralizada encargada de la ejecución de los procesos de consulta en el país (DPLF, 2015: 71-72). Sin embargo, en medio de los conflictos socioambientales crecientes por la expansión del modelo extractivo, las comunidades étnicas han denunciado la violación sistemática de sus derechos y muchas de ellas han optado por rechazar los procesos de consulta previa en sus territorios (Rodríguez, 2012; Rodríguez, 2014). Para algunos investigadores, la forma en que se desarrolla la consulta pre- 
via como mecanismo de participación de las comunidades étnicas evidencia una brecha entre el discurso legal-institucional y la práctica en la medida que: «El discurso en algunas sentencias sobre la participación y el fortalecimiento de la democracia se queda en el papel mientras en la práctica se expande la consulta como un espacio de negociación donde todo o casi todo tiene un precio» (Padilla, 2013: 267).

En el Perú, la falta de realización de Consultas Previas frente a proyectos extractivos de alto impacto ha llevado a graves y violentos enfrentamientos entre autoridades estatales y comunidades organizadas, como los ocurridos en Bagua en 2009 (De Echave, 2009; Sanborn y otros, 2016). ${ }^{3}$ El incumplimiento sistemático de la Consulta Previa se ha tratado de resolver con la promulgación de una Ley específica de Consulta Previa en 2011 y su Reglamento posterior, aunque se ha señalado como dicha Ley restringe el contenido del derecho a la consulta, desacatando los estándares internacionales (Leyva, 2016: 28-42; Ruiz, 2016). En Chile también se han emitido decretos que restringen aspectos del Convenio, como el Decreto N. ${ }^{\circ} 124$ del Ministerio de Planificación y el Decreto Supremo N. ${ }^{\circ}$ 66, el Ministerio de Desarrollo Social (DPLF, 2015: 27-38). Como precedente fundamental para América Latina, la Corte Interamericana sancionó al estado ecuatoriano por el incumplimiento de los estándares internacionales en la realización de la Consulta Previa a la comunidad indígena Kichwa de Sarayaku, por un proyecto de exploración y explotación de hidrocarburos en su territorio (CIDH, 2012).

A pesar de contar con un importante porcentaje de población indígena y un gran número de conflictos socioambientales por proyectos extractivos, los gobiernos mexicanos han omitido sistemáticamente la realización de Consultas Previas como ha quedado registrado en diversos informes oficiales. La Comisión Nacional de Derechos Humanos de México señaló en un comunicado de marzo de 2017 que es perentorio: «Saldar la deuda histórica que gobiernos y sociedad tienen con los pueblos y comunidades indígenas en materia de consulta previa, libre, informada, culturalmente adecuada y de buena fe» (CNDH, 2017: 1). Tal como se presenta en la tabla 1, el diseño institucional mexicano no permite la realización de Consultas Populares a escala local y tampoco han sido utilizadas de manera informal por las comunidades que se oponen a los proyectos, privilegiando otras formas de acción colectiva.

3 En medio del bloqueo por parte de los indígenas a la carretera panamericana en rechazo a la denominada Ley de la Selva, orientada a facilitar la venta de tierras y la explotación petrolera y gasífera en la Amazonía, se realizó un operativo militar de fuerzas especiales que dejó un saldo de 34 muertos, 158 heridos, decenas de presos y desaparecidos. Este hecho ocasionó un fuerte rechazo por la masacre tanto en el Perú como en el exterior -incluyendo un pronunciamiento de las Naciones Unidasexigiendo además la necesidad del diálogo. 
De todo lo anterior, lo más importante a destacar es que la ausencia de aplicación por parte de los gobiernos nacionales de la Consulta Previa, como mecanismos de democracia directa «desde arriba», ha desembocado en la movilización y acción colectiva de comunidades indígenas, que se ha unido a otras organizaciones y movimientos sociales, que reivindican el derecho a participar en las decisiones sobre el territorio que habitan frente al extractivismo imperante. La apelación a los mecanismos de democracia directa «desde abajo» y el uso no convencional de los mismos, se está convirtiendo en referente de la acción colectiva en América Latina como observamos en la tabla 2. En adelante, analizaremos la acción colectiva por país, donde se han utilizado mecanismos de consulta como estrategia de movilización y la interacción con las autoridades estatales.

\subsection{Perú}

Intensos conflictos sociales en rechazo a la expansión o a los efectos de los proyectos mineros fueron en aumento desde el año 2000 en el Perú, en la mayor parte de los casos, las movilizaciones tuvieron como respuesta del Gobierno nacional las declaratorias de Estados de Emergencia. La movilización social llevada a cabo entre el 2000 y 2003 en Tambogrande, departamento de Piura, marcó una referencia fundamental de las acciones colectivas frente al extractivismo en el país y en América Latina. En este distrito, las comunidades locales movilizadas en contra del proyecto minero de la empresa canadiense Manhattan Mineral Corporation defendieron la vocación agropecuaria de la región, considerada una de las principales zonas frutícolas del país, a través de marchas, recolección de firmas, enfrentamientos directos y ataques a los campamentos mineros, sin encontrar ninguna respuesta favorable por parte del Gobierno (Bebbintong, 2012: 67-87; Portugal, 2005). 
Tabla 2

Consulta Populares Locales/Vecinales/Comunitarias frente a proyectos extractivos

\begin{tabular}{|c|c|c|c|c|c|}
\hline \multirow[b]{2}{*}{ Pais } & \multirow[b]{2}{*}{$\begin{array}{c}\text { Municipio/Distrito/ } \\
\text { Localidad }\end{array}$} & \multirow[b]{2}{*}{$\begin{array}{l}\text { Fecha de } \\
\text { realización }\end{array}$} & \multicolumn{2}{|c|}{ Convocantes } & \multirow[b]{2}{*}{$\begin{array}{l}\text { Reconocimiento } \\
\text { de las autoridades } \\
\text { estatales }\end{array}$} \\
\hline & & & $\begin{array}{c}\text { Procedimiento } \\
\text { Legal } \\
\text { "desde arriba" }\end{array}$ & $\begin{array}{l}\text { Autoconvocada/ } \\
\text { Organización Social } \\
\text { "desde abajo" }\end{array}$ & \\
\hline \multirow{4}{*}{ Perú } & Tambogrande & $2 /$ jun 2002 & $\begin{array}{l}\text { Ordenanza } \\
\text { Minicipal }\end{array}$ & Organizaciones sociales & No \\
\hline & $\begin{array}{c}\text { Ayabaca y Huancabamba } \\
\text { Candavare }\end{array}$ & $\begin{array}{l}16 / \text { sept } 2007 \\
17 / \text { feb } 2008\end{array}$ & $\begin{array}{l}\text { Ordenamza } \\
\text { Minicipal } \\
\text { Ordenanza } \\
\text { Minicipal }\end{array}$ & $\begin{array}{l}\text { Frente por el Desarrollo } \\
\text { Sostenible de la Frontera } \\
\text { Norte del Perú } \\
\text { Organizaciones sociales }\end{array}$ & No \\
\hline & $\begin{array}{l}\text { Cocachacra, Punta del } \\
\text { Bombón, Dean Valdivia, } \\
\text { Islay-Matarani, Mejia }\end{array}$ & $27 /$ sept 2009 & $\begin{array}{l}\text { Ordenanzas } \\
\text { Minicipales }\end{array}$ & $\begin{array}{c}\text { Frente Amplio de } \\
\text { Defensa del Medio } \\
\text { Ambiente y Recursos } \\
\text { Naturales }\end{array}$ & No \\
\hline & Kañaris & $30 /$ sept 2012 & No & $\begin{array}{c}\text { Autoconvocada/ Lideres } \\
\text { comunitarios }\end{array}$ & NO \\
\hline \multirow{2}{*}{ Argentina } & Esquel & $23 /$ sept 2003 & $\begin{array}{l}\text { Ordenamza } \\
\text { Minicipal }\end{array}$ & $\begin{array}{l}\text { Asamblea de Vecinos } \\
\text { Autoconvocados (AVA) }\end{array}$ & $\mathbf{S}$ \\
\hline & Lancopue & 3/jun/2012 & $\begin{array}{l}\text { Ordenamza } \\
\text { Minicipal }\end{array}$ & $\begin{array}{l}\text { Asamblea de Vecinos } \\
\text { Autoconvocados de } \\
\text { Loncopue }\end{array}$ & $\mathbf{S}$ \\
\hline \multirow{4}{*}{ Guatemala } & Sipakapa & 18 jun 2005 & $\begin{array}{l}\text { Ordenanza } \\
\text { Minicipal }\end{array}$ & Organizaciones sociales & No \\
\hline & Mataquescuintla & 11/nov 2012 & $\begin{array}{l}\text { Ordenanza } \\
\text { Minicipal }\end{array}$ & Organizaciones sociales & $\mathbf{S}$ \\
\hline & $\begin{array}{c}\text { Totoricapán (34) } \\
\text { Huehuetango(30) } \\
\text { San Marcos (13) Santa } \\
\text { Rosa (12) Quiché (7) } \\
\text { Quetzaltenango (6) } \\
\text { Verapaz (2) Zacapa (2) } \\
\text { Guatemal a (2) Jalapa (1) } \\
\text { Izabal (1) Petén(1) }\end{array}$ & $2005-2015$ & No & $\begin{array}{l}\text { Autoconrocadas } \\
\text { Organizaciones } \\
\text { indigenas, Consejo de } \\
\text { los Pueblos de } \\
\text { Occidente, } \\
\text { organizaciones } \\
\text { ambientalitas }\end{array}$ & No \\
\hline & L $\propto$ Ángeles & 3 nov $/ 2013$ & No & $\begin{array}{l}\text { Autocom ocad a/Organiz } \\
\text { a. religiosas e ind genas }\end{array}$ & No \\
\hline Ecuador & $\begin{array}{c}\text { Tarqui y Victoria del } \\
\text { Portete }\end{array}$ & 2/oct/2011 & No & $\begin{array}{l}\text { Autocomrocada/ Jurta } \\
\text { de Aguas, Federación de } \\
\text { Organizaciones } \\
\text { Campesinas e Incigenas } \\
\text { del Azuay }\end{array}$ & No \\
\hline \multirow{3}{*}{ Colombia } & $\begin{array}{c}\text { Riedras } \\
\text { Tauramena }\end{array}$ & $\begin{array}{l}28 / \mathrm{jul} / 2013 \\
15 / \mathrm{dic} / 2013\end{array}$ & $\begin{array}{l}\text { Acuerdo } \\
\text { Minicipal } \\
\text { Acuerdo } \\
\text { Minicipal }\end{array}$ & $\begin{array}{l}\text { Organizaciones sociales } \\
\text { y campesinas } \\
\text { Organizaciones sociales } \\
\text { y campesinas }\end{array}$ & No \\
\hline & Cajamarca & $26 / \operatorname{mar} 2017$ & $\begin{array}{l}\text { Acuerdo } \\
\text { Municipal }\end{array}$ & $\begin{array}{c}\text { Organizaciones sociales } \\
\text { y campesinas }\end{array}$ & $\mathbf{S}$ \\
\hline & Cumaral & $4 /$ jun/2017 & $\begin{array}{l}\text { Acuerdo } \\
\text { Minicipal }\end{array}$ & $\begin{array}{c}\text { Organizaciones sociales } \\
\text { y campesinas }\end{array}$ & $\mathbf{S}$ \\
\hline
\end{tabular}

Fuente: Elaboración propia 
La ciudadanía movilizada decidió apelar a los mecanismos de democracia directa con el apoyo del alcalde municipal, como una nueva estrategia de acción colectiva. Mediante Ordenanza Municipal fue convocada una Consulta Vecinal donde se decidiría el apoyo o rechazo de la población al proyecto minero. El 2 de junio de 2002 fue llevada a cabo, con una participación electoral del 73 \% del padrón electoral, y con veedores nacionales e internacionales como acompañantes del proceso. Los resultados de la consulta fueron contundentes ya que el $98 \%$ de los votantes rechazaron el proyecto minero. El Gobierno central desestimó la consulta llevada a cabo y a través del ministro de Energía y Minas señaló su ilegalidad, catalogando los resultados como «no vinculantes» (Bebbintong, 2012: 67-87; Portugal, 2005; Fulmer, 2011: 44).

Las movilizaciones sostenidas continuaron defendiendo el derecho a decidir, legitimando la consulta realizada y rechazando cualquier otro escenario de interlocución. Finalmente, el Ministerio de Energía y Minas retiró la licencia de explotación a la empresa minera en 2003, argumentando imposibilidad de la empresa para demostrar capacidad financiera. Sin embargo, este hecho fue tomado como un triunfo de la acción colectiva de la comunidad de Tambogrande, sentando un precedente fundamental en torno a las Consultas Populares Locales como mecanismo de movilización frente al extractivismo (De Echave, 2009: 17-44).

La exigencia por el derecho a participar a través de la consulta como mecanismos de democracia directa, se convirtió en referente de extendidas acciones colectivas en todo el país. Desde el 2004 otros municipios del departamento de Piura, como Ayabaca y Huancabamba, se movilizaron en contra del proyecto de la Minera Majaz sa a través de marchas y protestas que fueron respondidas con violencia por parte de la fuerza pública y de trabajadores de la misma empresa. ${ }^{4}$ La acción colectiva liderada por el Frente por el Desarrollo Sostenible de la Frontera Norte del Perú exigió la realización de una Consulta Vecinal, la cual fue apoyada por el gobierno local y convocada mediante Ordenanza Municipal. En septiembre de 2007 fue llevada a cabo la consulta, participando cerca del $70 \%$ de la población habilitada para votar, donde el $95 \%$ manifestó su rechazo al proyecto minero ahora llamada Río Blanco Cooper sa y adquirida de manera mayoritaria por capitales chinos de la compañía Zijin Consortium (De Echave, 2009: 45-72).

4 En una marcha de 2005 fueron detenidos y torturados 32 comuneros (30 varones y dos mujeres), decenas de heridos y un asesinado. Después de ser denunciados los hechos por la Coordinadora Nacional de Derechos Humanos y pasados varios años de presiones, finalmente la minera Río Blanco Cooper sa aceptó indemnizar a 28 campesinos reconociendo su responsabilidad en los hechos de tortura realizados en la sede del campamento minero durante los días 1 y 3 de agosto de 2005. 
La apelación a la realización de consultas como estrategia de movilización fue utilizada igualmente en la provincia de Candavare, al sur del Perú, por el rechazo de la comunidad a la autorización de expansión en el uso del agua a la empresa minera Southern Copper Corporation. Mediante Ordenanza Municipal fue realizada la Consulta Vecinal, donde el $95 \%$ de los votantes se manifestaron en contra del proyecto minero (La República, 24 de febrero de 2008).

Una cuarta consulta se llevó a cabo en seis distritos de la provincia de Islay, convocada por el Frente Amplio de Defensa del Medio Ambiente y Recursos Naturales en 2009, para votar sobre la realización del proyecto Tía María de la empresa Southern Copper Peru Corporation. La consulta contó con el acompañamiento de diversas organizaciones, como la Confederación Nacional de Comunidades del Perú Afectadas por la Minería -coNACAMI-, Cooperacción, la Coordinadora Andina de Organizaciones Indígenas, Broererlijk Denle, Transparencia Civil y la Red Muqui. La Consulta no fue reconocida por el Gobierno nacional, al considerarla ilegal y no vinculante (Gutiérrez, 2011; Hoetmer y otros, 2013; Castillo, 2015).

Por último, la consulta autoconvocada por las organizaciones indígenas de la comunidad quechuahablante de Kañaris, que por años se ha movilizado exigiendo la realización de Consultas Previas, el 30 de septiembre de 2012. Esta Consulta Comunitaria se llevó a cabo por medio de voto secreto según el padrón electoral, con el acompañamiento de la Confederación Nacional de Comunidades del Perú Afectadas por la Minería -CONACAMI-, la Red Muqui, el Ministerio de Agricultura, entre otros. Al igual que las demás Consultas, la de Kañaris no fue reconocida por el Gobierno nacional, al considerarla ilegal y no vinculante (Sanborn y Paredes, 2015; Sanborn, y otros, 2016: 44-50).

Durante el gobierno de Humala -2011-2016- se llevó a cabo una estrategia de contención y restricción, mediante la actuación de diversas dependencias del gobierno central, para impedir y finalmente negar la realización de Consultas Populares, especialmente en la región de Cajamarca, donde las comunidades organizadas se han movilizado por años contra la realización del Proyecto Conga (Andina, 08 de febrero de 2013). ${ }^{5}$

5 En mayo de 2014, la Comisión Interamericana de Derechos Humanos -cidh- otorgó medidas cautelares a los líderes y lideresas de las acciones colectivas que se oponen al proyecto megaminero Conga que administra la empresa Yanacocha en Cajarmaca al considerar que se encontraban en grave peligro y riesgo, exigiendo al Estado peruano adoptar medidas para garantizar su vida e integridad personal. 


\subsection{Argentina}

En la ciudad de Esquel, ubicada en la provincia de Chubut, una amplia movilización social alrededor de la Asamblea de Vecinos Autoconvocados - AVA - se manifestó en contra de un proyecto de explotación de oro a cielo abierto de la empresa minera Meredian Gold. La acción colectiva de la Asamblea de Vecinos Autoconvocados recurrió a diversas estrategias de presión como marchas, plantones, interposición de recursos legales y administrativos, entre otras. Siguiendo el ejemplo de los ciudadanos de Tambogrande en Perú, la Ava decidió presentar una propuesta de Consulta Popular ante el Consejo Deliberante Local, la cual fue aprobada, no sin reticencias, para dar una salida institucional al conflicto social manifestado. El 23 de septiembre de 2003 fue realizada la Consulta Popular con un resultado contundente, donde el $81 \%$ de los votantes se manifestó en contra del megaproyecto minero. El Consejo Deliberante Local mediante Ordenanza Municipal declaró a Esquel «Municipio no tóxico y ambientalmente sustentable» convirtiéndose en referente a nivel nacional (Svampa, y otros, 2009; Marín, 2009).

Casi nueve años después, como respuesta a la presión y amplia movilización de la Asamblea de Vecinos Autoconvocados de Loncopué, se realizó un referéndum de cumplimiento obligatorio en la localidad, por medio del cual se sometió a votación la Ordenanza 1054/12 que prohíbe la minería a cielo abierto en la municipalidad. Con una participación del $72 \%$ del padrón electoral, los resultados señalaron un $82,08 \%$ a favor de la ordenanza que prohíbe la minería (Svampa y Viale, 2014:241-242; Wagner, 2015:102-103).

\subsection{Guatemala}

En Guatemala, a pesar de la ratificación del Convenio 169, la legislación interna circunscribe el derecho a la consulta de las comunidades étnicas a la «participación» de la población local en los estudios de impacto ambiental y social (DPLF, 2015: 76). Sumado a lo anterior, la inaplicabilidad de la Consulta Previa ha llevado a la realización de consultas comunitarias principalmente autoconvocadas, como estrategia establecida de acción colectiva por parte de los pueblos y organizaciones indígenas que se oponen a la realización de los proyectos extractivos (ORACACNUDH, 2012; Yagenova, 2012).

Desde el 2005, cuando se llevó a cabo la primera consulta comunitaria en Sipakapa, las comunidades locales, organizaciones y movimientos indí- 
genas han realizado más de 115 consultas en 74 municipios -12 departamentos- por tres vías diferentes de convocatoria. La primera de las vías son consultas llamadas «de buena fe», en las cuales se convoca a los habitantes de la comunidad desde las propias organizaciones o movimientos, retomando los principios establecidos en el Convenio de la OIT, se les pregunta a los asistentes si están de acuerdo con las actividades mineras en sus comunidades y se procede a una votación a mano alzada (Martínez, 2015: 267). La segunda vía son «consultas municipales» con mayor carácter institucional, apelando a la legitimidad del Convenio 169, pero también a los mecanismos de participación del Código Municipal, donde se establece que las autoridades municipales pueden convocar a las comunidades a través de una Ordenanza Municipal para que decidan sobre asuntos de carácter local. La tercera vía, llamada «consulta extraterritorial de buena fe», ha sido usada una sola vez en la ciudad de Los Ángeles en 2013, convocada por el Consejo Francisquense a todos los migrantes del pueblo Maya Kiché residentes en la ciudad, para que se pronunciaran mediante votación sobre la instalación de mineras canadienses en su territorio. Como resultado se obtuvieron 4.457 votos en contra de los proyectos mineros y cero votos a favor (Pérez, 2013).

Todas las consultas «de buena fe» han sido rechazadas por parte de los gobiernos al considerarse no vinculantes y carentes de legalidad, unido a una fuerte represión por medio de declaratorias de estado de sitio, así como la persecución y hostigamiento a líderes que se movilizan en contra de los proyectos mineros (Padilla, 2016).

\subsection{Ecuador}

En Ecuador, la defensa del agua frente a los proyectos mineros llevó a los ciudadanos movilizados de las parroquias de Tarqui y Victoria del Portete a decidir autoconvocar una consulta comunitaria el 2 de octubre de 2011. El uso de este mecanismo de democracia directa como estrategia de movilización tuvo el rechazo de las autoridades locales y el Gobierno nacional al ser considerada «ilegal e inconstitucional» (Pérez, 2011: 172-174). La consulta tuvo acompañamiento y veeduría nacional e internacional de diversas organizaciones sociales y no gubernamentales, sus resultados fueron contundentes con un $98 \%$ en oposición al desarrollo de proyectos mineros en el Páramo de Kimsamkocha. Sin embargo, la respuesta del Gobierno nacional no se hizo esperar, Rafael Correa visitó la región, deslegiti- 
mando sus resultados, subrayó que solo el presidente tiene potestad para determinar la política minera, y ante las protestas fue encarcelado el dirigente social Leopoldo López, presidente de la Federación de Organizaciones Indígenas y Campesinas del Azuay (FOA) (El Comercio, 10 de octubre de 2011; El Universo, octubre 27 de 2011). ${ }^{6}$

\subsection{Colombia}

A partir de 2010, en Colombia se activó un ciclo de movilización en un nuevo contexto económico de auge megaminero donde la ciudadanía, a través de diversos colectivos sociales, se ha movilizado en defensa del derecho a participar, reivindicando la posibilidad de decidir sobre las transformaciones económicas que se está llevando a cabo en sus territorios (Hincapié y López, 2016).

En el departamento de Santander, ciudadanos de diferentes municipios iniciaron una intensa movilización en oposición a los proyectos mineros de la empresa canadiense Greystar en el Páramo de Santurbán. La exigencia de realización de una Consulta Popular, para declarar como bienes de interés públicos los ecosistemas que proveen de agua a la región e impedir el desarrollo de proyectos megamineros, fue negada a la ciudadanía movilizada por diversas vías (Martínez, 2014). ${ }^{7}$

Siguiendo el ejemplo de la acción colectiva de Santander, en diferentes localidades del país la realización de Consultas Populares se constituyó en una importante estrategia de movilización local en resistencia a los proyectos extractivistas. A través del decreto 0934 de mayo de 2013, el Gobierno nacional intentó frenar la realización de Consultas Populares, al establecer que los gobiernos locales o regionales, así como sus comunidades, no pueden oponerse a que se desarrollen proyectos mineros en sus territorios.

A pesar de lo anterior, la presión de los colectivos y organizaciones sociales municipales en el municipio de Piedras, departamento del Tolima, llevó al alcalde municipal a convocar la realización de una Consulta Popu-

6 No puede dejarse sin mencionar el intento, hasta ahora infructuoso, de los colectivos sociales por convocar a una Consulta Popular a nivel nacional sobre los proyectos de hidrocaburos en el parque nacional Yasuní en la cuenca amazónica, el cual ha sido impedido en los hechos por el Gobierno nacional y sus aliados contradiciendo los principios constitucionales.

7 La petición de Consulta Popular fue negada por el Tribunal Administrativo de Santander en 2011. En el departamento de Norte de Santander que comparte parte del Páramo de Santurbán, la posibilidad de Consulta Popular fue aprobada, pero la Registraduría Nacional argumentó falta de presupuesto y no fue realizada. 
lar en julio de 2013. Como resultado de la Consulta Popular, el $92.2 \%$ de la comunidad votó en contra del megaproyecto minero de la empresa AngloGold Ashanti. En diciembre del mismo año, en el municipio de Tauramena departamento del Casanare, a través de otra Consulta Popular, el $96 \%$ de los votantes se manifestó en contra de las actividades relacionadas con la explotación de hidrocarburos en sus territorios (El Espectador, 25 de agosto de 2014).

Para el Gobierno nacional las consultas fueron ilegales, pues «el subsuelo pertenece a la nación». La Procuraduría Provincial de Ibagué abrió investigaciones en contra del alcalde de Piedras y los miembros del Concejo Municipal por considerar que se extralimitaron en sus funciones al convocar a la Consulta Popular (El Tiempo, 2 de abril de 2014). Así mismo, aduciendo faltas disciplinarias, la Procuraduría General de la Nación abrió también investigación en contra del alcalde de Tauramena, al considerar que la convocatoria a la Consulta Popular violó el decreto 0934 de 2013.

Una disputa jurídica se ha llevado a cabo desde entonces en el país, alrededor de la Consulta Popular local como mecanismo de democracia directa. La Corte Constitucional, a través de las sentencias C-035 y T-445/2016, ambas de 2016, subrayó la autonomía constitucional que tienen los municipios para decidir sobre sus suelos y ordenar el territorio, precisando que «los entes territoriales poseen la competencia para regular el uso del suelo y garantizar la protección del medio ambiente, incluso si al ejercer dicha prerrogativa terminan prohibiendo la actividad minera». Estas sentencias sentaron un precedente fundamental de legitimidad para las Consultas Populares locales, las cuales fueron reactivadas en los escenarios locales.

Especialmente relevante fue la movilización que permitió, el 26 de marzo de 2017, la realización de una Consulta Popular en el municipio de Cajamarca -Tolima-, donde el $97.92 \%$ se pronunció en contra proyecto minero La Colosa, de la empresa multinacional AngloGold Ashanti. Esta Consulta Popular tuvo un especial seguimiento y debate en los medios de comunicación nacionales e internacionales, en la medida en que se decidió sobre la realización de uno de los yacimientos de oro más grandes del mundo, que pretende ser explotado, por medio de una mina a cielo abierto, en una Zona de Reserva Forestal con 160 nacimientos de agua y la cuenca alta del río Coello, que abastecen de agua a varios municipios del departamento y al distrito arrocero más grande del país.

Tanto la realización de la consulta como su resultado sentaron un claro precedente para Colombia y para la región sobre la legitimidad de los MDD, como medio de expresión y dispositivo para la toma de decisiones partici- 
pativas sobre el desarrollo territorial. A partir de allí fueron aprobadas nuevas consultas populares locales. El 4 de junio de 2017 en Cumaral, Departamento del Meta, se preguntó a la ciudadanía si estaba de acuerdo o no con que en su territorio la industria petrolera llevara a cabo perforación exploratoria, exploración sísmica y producción de hidrocarburos; el 97.04 $\%$ de las personas que participaron rechazaron los proyectos extractivistas, legitimando la acción colectiva y los MDD como vehículos de expresión de las decisiones ciudadanas.

\section{CONCLUSIONES}

El nivel local es la matriz en la cual se gesta la democracia participativa de la sociedad, es allí donde se realiza en primera instancia el vínculo entre el ciudadano y la res publica. A pesar de la retórica participativa que ha dominado la agenda democrática de los últimos treinta años en América Latina, el análisis de los conflictos socioambientales en todos los países señala que las demandas por participar y decidir sobre el desarrollo territorial local, a través de mecanismos de democracia directa «desde abajo» parece sucumbir ante la enorme potestad de los poderes institucionalizados «desde arriba», a favor de los intereses corporativos.

La Consulta Previa, como mecanismo utilizado «desde arriba» por gobiernos y empresas, se ha convertido en un procedimiento más de las exigencias legales y burocráticas establecidas en el desarrollo de los proyectos extractivos, donde las comunidades no tienen ninguna posibilidad real de influencia. Cuando los mecanismos de democracia directa son exigidos y apropiados por la ciudadanía en sus entornos locales, se estigmatiza su utilización y son socavados y cuestionados los principios sobre los cuales se erigen. En ese sentido, las consultas impulsadas «desde abajo» han sido deslegitimadas, consideradas ilegales y no vinculantes, aun cuando se apeguen a los procedimientos legalmente establecidos.

En toda América Latina, un continente sumido en el consenso extractivista, los gobiernos nacionales se oponen de manera decidida a la implementación de los mecanismos democráticos de participación para consultar a las comunidades afectadas directamente por los proyectos extractivos. Basta observar los graves incidentes ocurridos hace poco en proyectos mineros de Brasil y Argentina, para advertir que los planes y programas de gobierno en los cuales se sustentan las políticas extractivistas, difícilmente se ajustan a los marcos constitucionales que garantizan derechos fundamentales a sus 
ciudadanos. La intensidad de los daños ya causados en el deterioro de la calidad de vida las comunidades locales donde se han desarrollado grandes proyectos -como La Guajira en Colombia, el Gran San Juan en Argentina, Zacatecas y Sonora en México, Cerro de Pasco en Perú-, hacen evidente las graves violaciones a los derechos fundamentales, a los derechos intergeneracionales y el detrimento patrimonial de toda la ciudadanía por la explotación de los recursos naturales.

A pesar de lo anterior, en este artículo hemos demostrado cómo la apropiación de los mecanismos de democracia directa a escala local se ha convertido en una importante estrategia de movilización, extendida en toda América Latina, como oposición a los proyectos extractivistas. La utilización no convencional de dichos mecanismos ha puesto en evidencia la arbitrariedad de las políticas económicas de los gobiernos de nivel central, que disponen el uso y distribución de los recursos naturales, sin importar el impacto económico, social y cultural que tiene para las comunidades que habitan en los territorios. Gobiernos locales, comunidades étnicas y campesinas, ambientalistas, académicos y activistas de derechos humanos, han defendido una posición expansiva de los derechos políticos, donde se rechaza la imposición por parte del nivel central de la planeación del desarrollo territorial y la adecuación legal para permitir la explotación de recursos naturales por parte de grandes empresas, sin considerar la opinión de las comunidades locales que son, en últimas, quienes asumen los inmensos costos y pasivos ambientales inconmensurables que deja la minería.

Aquí se ha presentado un panorama general de América Latina. El paso siguiente será profundizar en los factores asociados a las particularidades de los contextos locales, que nos ayuden a comprender mejor las condiciones que favorecen o desincentivan la acción colectiva de la sociedad civil, así como las posibilidades reales de participación ciudadana en la planeación de desarrollo local-regional. Es fundamental la fuerza de la movilización exigiendo más y mejor democracia, así como el desarrollo de múltiples mecanismos de democracia directa que hagan posible la participación ciudadana efectiva en el planeamiento del desarrollo local. La reivindicación de la participación democrática en los escenarios locales forma parte de las promesas no cumplidas en los procesos de democratización asociados a la descentralización del poder, como parte fundamental de las reformas promovidas en las últimas décadas. Es preciso recordar que el derecho a decidir, como condición del ejercicio de la ciudadanía, es una aspiración legítima en un orden democrático. 


\section{REFERENCIAS BIBLIOGRÁFICAS}

Acosta, A. (2012): «Extractivismo y neoextractivismo: dos caras de la misma maldición», en LANG y CHÁvEz (coord.) (2012): Más Allá del Desarrollo: Grupo Permanente de Trabajo sobre Alternativas al Desarrollo, Quito, Abya Yala, Fundación Rosa Luxemburg.

ANAYA, J. (2011): Informe del Relator Especial de Naciones Unidas sobre los derechos de los pueblos indígenas, Nueva York, Naciones Unidas, Consejo de Derechos Humanos.

Andina (2013): "Ministro del Ambiente: Defensoría ya aclaró que un referéndum sobre Conga es inválido", 8 de febrero de 2013. Disponible en: http://www.andina.com.pe/agencia/noticia-ministro-del-ambiente-defensoria-ya-aclaro-un-referendum-sobre-conga-es-invalido-446659.aspx

Arques, F. (2014): Mecanismos de Democracia Directa en Argentina a nivel sub-nacional: un recurso latente e ignorado, Working Papers Series 46, Centre for Democracy Studies, Aarau (ZDA), University of Zurich.

Bebintong, A. (2012): "Social conflict and emergent institutions. Hypotheses from Piura, Peru», en BebBintong, A. (ed.) (2012): Extractive Industries, Social Conflict and Economic Development: Evidence from South America, London, Routledge.

BERNALES, E. (2006): «El derecho humano a la participación política», Derecho PUCP, 59, pp. 9-32.

Bollier, D. (2014): Think Like a Commoner. A Short Introduction to the Life of the Commons, Canadá, New Society Publishers.

Castillo, K. (2015): "Análisis de caso: conflicto en torno a la instalación del proyecto minero Tía María en el departamento de Arequipa, Perú», en Bedoya, L. (ed.). (2015): Transformación de Conflictos. Aportes al análisis y abordaje de conflictos para el desarrollo sostenible, Congreso de la República Lima, ProDiálogo, Universidad Antonio Ruiz Montoya, pp. 225-249.

Comisión Nacional de Derechos Humanos (2017): La Consulta Previa, libre e informada a comunidades y pueblos indígenas es deuda bistórica de gobiernos y sociedad que les impide ejercer sus derechos. Comunicado de Prensa DGC/088/17.

Congreso de la República de Guatemala (2002): Decreto 12-2002. Código Municipal, Guatemala, Congreso de la República. 
Corte Interamericana de Derechos Humanos (2012): Caso Pueblo Indígena Kichwa de Sarayaku vs. Ecuador, Fondo y reparaciones, Sentencia de 27 de junio de 2012.

DE ECHAVE, J. (2009): Minería y conflicto social, Lima, IEP, CIPCA, CIES, CBC.

De Sousa, B. (2014): Derechos bumanos, democracia y desarrollo, Bogotá, Editorial Dejusticia.

DeZALAY,Y. y GARTH, B. (2008): «Las paradojas de un imperialismo de la virtud cívica: de la internacionalización de los derechos humanos a la profesionalización del activismo jurídico», en Vecchioli, V. y SAntamaría, A. (eds.) (2008): Derechos Humanos en América Latina. Mundialización y circulación internacional del conocimiento experto jurídico, Bogotá, Universidad del Rosario, CEPI.

Due Process of Law Foundation (2015): Derecho a la consulta y al consentimiento libre e informado en América Latina. Washington, DPLF, OXFAM.

El Comercio (2011): «El gobierno está inquieto por la consulta minera», 10 de octubre de 2011. Disponible en http://www.elcomercio.com/actualidad/politica/gobierno-inquieto-consulta-minera.html [Última consulta 20 de enero de 2017]

El Espectador (2014): «Hace un año Piedras le dijo no a la minería: ¿de qué sirvió?», 25 de agosto de 2014. Disponible en: http://www.elespectador. com/noticias/nacional/hace-un-ano-piedras-le-dijo-no-mineria-de-sirvioarticulo-512776 [Última consulta 23 de enero de 2017]

EL Tiempo (2014): «Abren indagación al alcalde de Piedras por Consulta minera», 2 de abril de 2014. Disponible en: http://www.eltiempo.com/colombia/otras-ciudades/investigan-al-alcalde-de-piedras-por-consultaminera/13768435 [Última consulta 21 de mayo de 2016]

EL UnIVERSO (2011): «Liberado dirigente apresado tras presunta agresión al presidente Correa», octubre 26 de 2011. Disponible en: http://www. eluniverso.com/2011/10/26/1/1447/liberado-dirigente-apresado-traspresunta-agresion-presidente-correa.html

Fulmer,A. (2011): «La consulta a los pueblos indígenas y su evolución como herramienta de negociación política en América Latina. Los casos de Perú y Guatemala», Apuntes 68, pp. 37-62.

GudynAs, E. (2013): «Extracciones, extractivismos y extrahecciones. Un marco conceptual sobre la apropiación de recursos naturales», Observatorio del Desarrollo, CLAEs, 18, pp. 1-17.

Gudynas, E. (2014): «Conflictos y extractivismos: conceptos, contenidos y dinámicas», Decursos. Revista en Ciencias Sociales, 27-28, pp. 79-115. 
GutiérRez, J. (2011): «Las razones de la lucha por el Valle de Tambo», en Valle del Tambo-Islay. Territorio, agua y derechos locales en riesgo por la minería, Lima, Cooperacción, Red Muqui.

Harvey, D. (2004): El nuevo imperialismo, Madrid, Akal.

Held, D. (1997): «Ciudadanía y autonomía», La Política, 3, pp. 41-67.

HinCAPIÉ, S. y LóPEz, J. (2016): «Derechos humanos y bienes comunes. Conflictos socioambientales en Colombia", Desacatos. Revista de Antropología Social, 51, pp. 130-141.

Hoetmer, R. y otros (2013): Minería y movimientos sociales en el Perú. Instrumentos y propuestas para la defensa de la vida, el agua y los territorios, Lima, Programa de Estudios sobre Democracia y Transformación Global, ACsur.

La República (2008): «Candavare enviará resultado de consulta popular al Congreso», 24 de febrero de 2008. Disponible en: http://larepublica. pe/24-02-2008/candarave-enviara-resultados-de-consulta-popular-al-congreso

LEFF, E. (2004): «El movimiento ambiental por la reapropiación social de la naturaleza: seringueiros, zapatistas, afrodescendientes y pueblos indígenas de América Latina», Racionalidad ambiental. La reapropiación social de la naturaleza, México, Siglo xxi Editores.

LEYVA, R. (2016): «Derechos colectivos, participación indígena y consulta previa», en VARGAS, K. (Comp.) (2106): La implementación del derecho a la consulta previa en el Perú. Aportes para el análisis y la garantía de los derechos colectivos de los pueblos indígenas. Lima, GIZ.

Lissidini, A. (2015): «Democracia directa en América Latina: avances, contradicciones y desafíos», en Minnaert, A. y Endara, G. (coords.) (2015): Democracia participativa e izquierdas. Logros contradicciones y desafíos, Quito, FES-ILDIS, pp.120-189.

Lissidini, A. y otros (comp.) (2014): Democracias en movimiento. Mecanismos de democracia directa y participación en América Latina, México, Universidad Nacional Autónoma de México, Centro de Investigaciones sobre Democracia Directa, Instituto Internacional para la Democracia y Asistencia Electoral.

Marín, M. C. (2009): «El "no a la mina" de Esquel como acontecimiento: otro mundo posible», en Svampa, M. y Antonelli, M. (eds.) (2009): Minería transnacional, narrativas del desarrollo y resistencias sociales, Buenos Aires, Biblos. 
Martínez, E. (2014): «El páramo de Santurbán, patrimonio nuestro y de la humanidad: en peligro inminente», Caja de Herramientas, 00395, pp. 11-17.

Martínez, M. I. (2015): «Reconocimiento sin implementación. Un balance sobre los derechos de los pueblos indígenas en América Latina», Revista Mexicana de Ciencias Políticas y Sociales, Universidad Nacional Autónoma de México, Nueva Época, Lx, 224, pp. 251-278.

Martínez-Alier, J. (2011): El ecologismo de los pobres. Conflictos ambientales y lenguajes de valoración, Barcelona, Icaria editorial.

O'Connor, J. (2001): Causas naturales. Ensayos de Marxismo Ecológico, México, Siglo xxI.

Oficina Regional para América Central del Alto Comisionado de las Naciones Unidas para los Derechos Humanos (2012): Diagnóstico sobre la situación de los derechos humanos de los pueblos indígenas en América Central, Panamá, Oficina del Alto Comisionado de las Naciones Unidas para los Derechos Humanos, Embajada de Noruega.

Padilla, G. (2013): «Consulta previa en Colombia y sus desarrollos jurisprudenciales. Una lectura desde los pueblos indígenas, las empresas y el Estado", Anuario de derecho constitucional Latinoamericano, XIX, pp. 353-379.

- «Los pueblos indígenas y la consulta previa: ¿normatización o emancipación? Una mirada desde Guatemala», Revista Colombiana de Sociología, 39, 1, pp. 193-219.

Pérez, E. (2013): «EU: Consulta de Buena Fe del pueblo Maya Kiché», Prensa Comunitaria Km 169, comunicación desde los pueblos en Guatemala. 5 de Noviembre de 2013. Disponible en https://comunitariapress. wordpress.com/2013/11/05/cronica-consulta-de-buena-fe-desde-los-eu/ [Última visita 18 de enero 2017]

Pérez, G. (2012): Agua u Oro. Kimsakocha, la resistencia por el agua, Cuenca, Universidad Estatal de Cuenca.

PoRtugal, C. (2005): Gobernanza en el acceso a la actividad minera a los recursos naturales locales: el caso Tambogrande, Lima, Grupo de Investigaciones Económicas.

Procuraduría General de la Nación. Oficio ad-Mhr-070 enviado a Guillermo Alfonso Jaramillo, alcalde de Ibagué, 8 de febrero de 2016. Disponible en: https://es.scribd.com/doc/300226167/Oficio-Procuraduria-a-alcalde-de-Ibague [Última consulta, 16 de mayo de 2016] 
Puyana, A. M. (2016): Consulta previa y modelos de desarrollo: juego de espejos. Reflexiones a propósito de los 25 años del Convenio 169 de la oIT, Bogotá, Editorial Gente Nueva.

Rodríguez, C. (2012): Etnicidad.gov. Los recursos naturales, los pueblos indígenas y el derecho a la consulta previa en los campos sociales minados, Bogotá, Centro de Estudios de Derecho, Justicia y Sociedad.

Rodríguez, C. y Morris, M. (2010): La consulta previa a pueblos indígenas. Los estándares del derecho internacional, Bogotá, Universidad de los Andes.

Rodríguez, G. (2014): De la consulta previa al consentimiento libre, previo e informado a pueblos indígenas en Colombia, Bogotá, GIz, Universidad del Rosario.

Ruiz, J. C. (2016): ¿Por qué la Consulta Previa no funciona en proyectos extractivos en el Perú? Lima, Instituto de Defensa Legal. Recuperado de: https://dplfblog.com/2016/05/03/por-que-la-consulta-previa-no-funciona-en-proyectos-extractivos-en-el-peru/ [Última consulta 23 de enero de 2017]

Ruth, S. y Svampa, M. (2017): Let the People Rule? Direct Democracy in the Twenty-First Century, Colchester, ECPR Press

Sanborn, C. y Paredes, A. (2015): Getting it Right? Challenges to Prior Consultation in Peru, University of Queensland, Center for Social Responsibility in Mining.

SAnborn, C y otros (2016): La consulta previa en el Perú: avances y retos, Lima, Universidad del Pacífico.

SEN, A. (2010): La idea de la justicia, México, Taurus.

SIKKINK, K. (2014): «Latin American Countries as Norm Protagonists of the Idea of International Human Rights», Global Governance, 20.3, pp. 389404.

STAMmERs, N. (2009): Human rights and social movements, London, Pluto Press.

Svampa, M. (2013): "Consenso de los Commodities y lenguajes de valoración en América Latina», Nueva Sociedad, 244, pp. 30-46.

Svampa, M. y Viale, E. (2014): Maldesarrollo. La Argentina del extractivismo $y$ el despojo, Buenos Aires, Katz Editores.

SvAmpa, M. y otros (2009): "Los movimientos contra la minería metalífera a cielo abierto: escenarios y conflictos. Entre el "efecto Esquel" y el "efecto La Alumbrera"», en Svampa, M y Antonelli, M. (eds.) (2009): Minería transnacional, narrativas del desarrollo y resistencias sociales, Buenos Aires, Biblos. 
Tilly, C. (2007): Democracy, Cambridge, Cambridge University Press.

Toledo, V. y otros (2013): «Conflictos socioambientales, resistencias ciudadanas y violencia neoliberal en México», Ecología política, 46, pp. 115124.

Tribunal Supremo de Elecciones (1998): Manual para la realización de consultas populares a nivel cantonal $y$ distrital, Guatemala, Tribunal Supremo de Elecciones.

WAGNER, L. (2015): «Conflictos socioambientales por minería a gran escala en Argentina: debates sociotécnicos, movilizaciones sociales e institucionalidad ambiental», en Guimaraes, P. E. y Pérez, J. D. (eds.) (2015): Conflitos Ambientais na Indústria Mineira e Metalúrgica: o passado e o presente, Río de Janeiro, Universidade de Évora.

YAGENOVA, S. V. (coord.) (2012): La industria extractiva en Guatemala: políticas públicas, derechos bumanos y procesos de resistencia popular en el período 2003-2011, Guatemala, FLACso.

ZovatTo, D. (2014): «Las instituciones de la democracia directa», en LissidinI, A. y otros (comp.) (2014): Democracias en movimiento. Mecanismos de democracia directa y participación en América Latina, México, Universidad Nacional Autónoma de México, Centro de Investigaciones sobre Democracia Directa, Instituto Internacional para la Democracia y Asistencia Electoral. 